\title{
An Evaluation of Morphological Changes and Deformability of Suspended Red Blood Cells Prepared Using Whole Blood with Different Hemoglobin Levels of Tibetans
}

\author{
Rui Zhong ${ }^{a}$ Dingding Han ${ }^{a}$ Xiaodong Wu ${ }^{b}$ Hong Wang ${ }^{a}$ Wanjing Li $^{a}$ \\ Zeng $\mathrm{He}^{\mathrm{a}}$ Xuejun Zhang ${ }^{\mathrm{a}}$ Jiaxin Liu ${ }^{\mathrm{a}}$ \\ a Institute of Blood Transfusion, Peking Union Medical Collage, Chinese Academy of Medical Science,

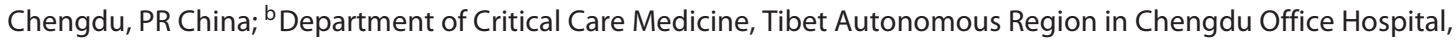 \\ Chengdu, PR China
}

\section{Keywords}

Morphological changes · Deformability · Suspended red blood cells

\begin{abstract}
Background: The hypoxic environment stimulates the human body to increase the levels of hemoglobin (HGB) and hematocrit and the number of red blood cells. Such enhancements have individual differences, leading to a wide range of HGB in Tibetans' whole blood (WB). Study Design: WB of male Tibetans was divided into 3 groups according to different HGB (i.e., A: $>120$ but $\leq 185 \mathrm{~g} / \mathrm{L}, \mathrm{B}:>185$ but $\leq 210$ $\mathrm{g} / \mathrm{L}$, and $\mathrm{C}:>210 \mathrm{~g} / \mathrm{L}$ ). Suspended red blood cells (SRBC) processed by collected WB and stored in standard conditions were examined aseptically on days 1, 14, 21, and 35 after storage. The routine biochemical indexes, deformability, cell morphology, and membrane proteins were tested. Results: Mean corpuscular volume, adenosine triphosphate, $\mathrm{pH}$, and deformability were not different in group A vs. those in storage $(p>0.05)$. The increased rate of irreversible morphology of red blood cells was different among the 3 groups, but there was no difference in the percentage of red blood cells with an irreversible morphology after 35 days of storage. Group $C$ performed better in terms of osmotic fragility and showed a lower rigid index than group A. Furthermore, SDSPAGE revealed similar cross-linking degrees of cell membrane protein but the band 3 protein of group $C$ seemed to
\end{abstract}

experience weaker clustering than that of group $A$ as detected by Western Blot analysis after 35 days of storage. Conclusions: There was no difference in deformability or morphological changes in the 3 groups over the 35 days of storage. High HGB levels of plateau SRBC did not accelerate the RBC change from a biconcave disc into a spherical shape and it did not cause a reduction in deformability during 35 days of preservation in bank conditions.

๑ 2021 S. Karger AG, Basel

\section{Introduction}

Donated whole blood (WB) is usually separated into various products for various clinical transfusion purposes. Suspended red blood cells (SRBC) are the most commonly transfused blood product $[1,2]$. Blood donations for clinical use are routinely stored for 35-42 days, depending on the composition of the anticoagulant-preservative solution [3]. During storage, possible changes in function and structure may cause increased risks in clinical blood transfusion. These alternations are termed storage lesions and can be classified into the following 3 broad categories: biochemical, immunological, and biomechanical changes [4]. Biomechanical alternations mainly in-

R.Z. and D.H. are joint first authors. 
clude changes in deformability and osmotic fragility, which are affected by cell morphology [5]. Deformability and osmotic stresses of the erythrocyte membrane are important guarantees for red blood cells (RBC) through capillaries and oxygen delivery to the tissue [6]. The double concave disc shape of erythrocyte has the characteristics of a large area and a small volume, which is an important determinant of blood flow [7]. During the process of preservation, $\mathrm{RBC}$ membrane loss may lead to irreversible changes in the ratio of surface area to volume. This affects the gross morphology of RBC and thus has serious implications for RBC deformability, resulting in ineffective microcirculatory transportation [8].

It is known that the oxygen partial pressure in the atmosphere decreases with elevation in altitude. When individuals ascend to the high altitude (HA), the hypoxic environment stimulates the human body to increase the levels of hematocrit (Hct) and hemoglobin (HGB) and the number of RBC [9]. The increased HGB is potentially important for improving the oxygen-carrying capacity of RBC. Such an enhancement in HGB has individual differences. Wu et al. [10] reported that the HGB levels of normal Tibetan females ranged from 134 to $157 \mathrm{~g} / \mathrm{L}$ and those of males ranged from 134 to $147 \mathrm{~g} / \mathrm{L}$, depending on the altitude. Zhang et al. [11] divided WB samples of Tibetan volunteers into 4 groups according to different HGB values, which could be $>184$ or $<166 \mathrm{~g} / \mathrm{L}$. Our team previously reported that the WB of Tibetan males had a HGB level of 165.62 $\mathrm{g} / \mathrm{L}$ [12]. All of these data indicate that the HGB levels of Tibetans may have a wide range. Currently, the research on $\mathrm{RBC}$ storage lesions is mainly focused on SRBC prepared using blood from plain residents [13]; however, the storage quality of SRBC from Tibetans' blood with different HGB levels is mostly unknown. Thus, the objectives of this study were to compare the erythrocyte morphology and deformability of SRBC from Tibetan WB with different HGB levels during storage in bank conditions, and to discuss the safety of clinical transfusion in the Tibet plateau.

In this study, we divided the WB of Tibetans into 3 groups according to the HGB level. The collected WB was processed into SRBC and stored in standard blood banking conditions [14]. The SRBC were examined aseptically on days $1,14,21$, and 35 after storage. The following parameters were tested: mean corpuscular volume (MCV), extracellular $\mathrm{pH}$, adenosine triphosphate (ATP), osmotic fragility, deformability, band 3 protein metabolism, and cell morphology.

\section{Materials and Methods}

WB Collection, RBC Processing, and Storage

WB harvested from the Tibet Autonomous Region in Chengdu Office Hospital was divided into 3 groups (Table 1). The inclusion criteria were that all volunteers had to be aged 18 years or older
Table 1. Classification at baseline

\begin{tabular}{llll}
\hline Group & A & B & C \\
\hline HGB, g/L & $>120$ but $\leq 185$ & $>185$ but $\leq 210$ & $>210$ \\
Samples, $n$ & 15 & 12 & 12 \\
Age, years & $40.40 \pm 8.74$ & $40.75 \pm 8.53$ & $43.33 \pm 7.65$ \\
Altitude, $m$ & $3,722 \pm 469$ & $3,680 \pm 437$ & $3,769 \pm 354$ \\
\hline
\end{tabular}

Values are presented as means \pm SD or numbers unless otherwise stated.

Table 2. Composition of CPDA-1 and MAP

\begin{tabular}{lll}
\hline Composition & CPDA-1 & MAP \\
\hline Sodium citrate, mM & 89 & 5.1 \\
Acid citrate, mM & 17 & 1.0 \\
Sodium phosphate, mM & 5.8 & - \\
$\mathrm{NaH}_{2} \mathrm{PO}_{4}, \mathrm{mM}$ & - & 7.8 \\
$\mathrm{Glucose}_{\mathrm{mM}}$ & 177 & 40 \\
$\mathrm{NaCl}, \mathrm{mM}$ & - & 85 \\
Adenine, mM & 2.0 & 1.0 \\
Mannitol, mM & - & 80 \\
\hline
\end{tabular}

and unrelated. Information on the weight and height of the donors was not supplied by the hospital. They were healthy donors, and this was their first time donating. All of the donors were male Tibetans, who had lived in an HA environment $(>3,400 \mathrm{~m})$ for $>1$ year. The age of the donors ranged from 19 to 60 years. The samples were divided into categories as shown in Table 1 . WB $(200 \mathrm{~mL} \pm 10 \%)$ was collected into blood collection packs containing citrate-phosphate-dextrose-adenine-1 (CPDA-1) anticoagulant (28 mL; Nan Geer Biomedical Corporation, Sichuan, China). Each bag of WB was centrifuged at $3,500 \mathrm{~g}$ for $15 \mathrm{~min}$ at $4{ }^{\circ} \mathrm{C}$. The plasma was removed, and $50 \mathrm{~mL}$ mannitol-adenine-phosphate (MAP; see Table 2 for the additive solution composition) was added to the packed RBC to obtain the SRBC. The SRBC units were stored in standard blood banking conditions [14] at $2-6{ }^{\circ} \mathrm{C}$ and analyzed on days $1,14,21$, and 35 of storage.

\section{Biochemical Analysis}

On each day of sample collection, blood examinations were performed using an automated hematology analyzer (BC-5800; Mindray, Shenzhen, China), and Hct levels and MCV were examined. Extracellular $\mathrm{pH}$ was measured with a $\mathrm{pH}$ meter (FE20; Mettler Toledo, Switzerland). ATP was assessed using commercial ATP kits according to the recommended protocols.

\section{Osmotic Fragility}

Osmotic fragility was determined using a series of diluted sodium chloride solutions with concentrations ranging from 3.0, 4.0, $4.2,4.4,4.6,4.8,5.0,5.2,5.4,6.0,7.0$, and $8.0 \mathrm{~g} / \mathrm{L}$ to $9.0 \mathrm{~g} / \mathrm{L}$. Briefly, $30 \mu \mathrm{L}$ RBC with $50 \%$ Hct was added to $3,000 \mu \mathrm{L}$ of each diluted sodium chloride solution and incubated at room temperature for $30 \mathrm{~min}$, followed by centrifugation at $1,000 \mathrm{~g}$ for $5 \mathrm{~min}$. Then, the free $\mathrm{Hb}$ in the supernatant was measured using a spectrophotometer at a wavelength of $540 \mathrm{~nm}$. Distilled water was taken as reference for $100 \%$ hemolysis, and the concentration of sodium chloride necessary to induce $50 \%$ hemolysis was defined as the osmotic fragility index. 


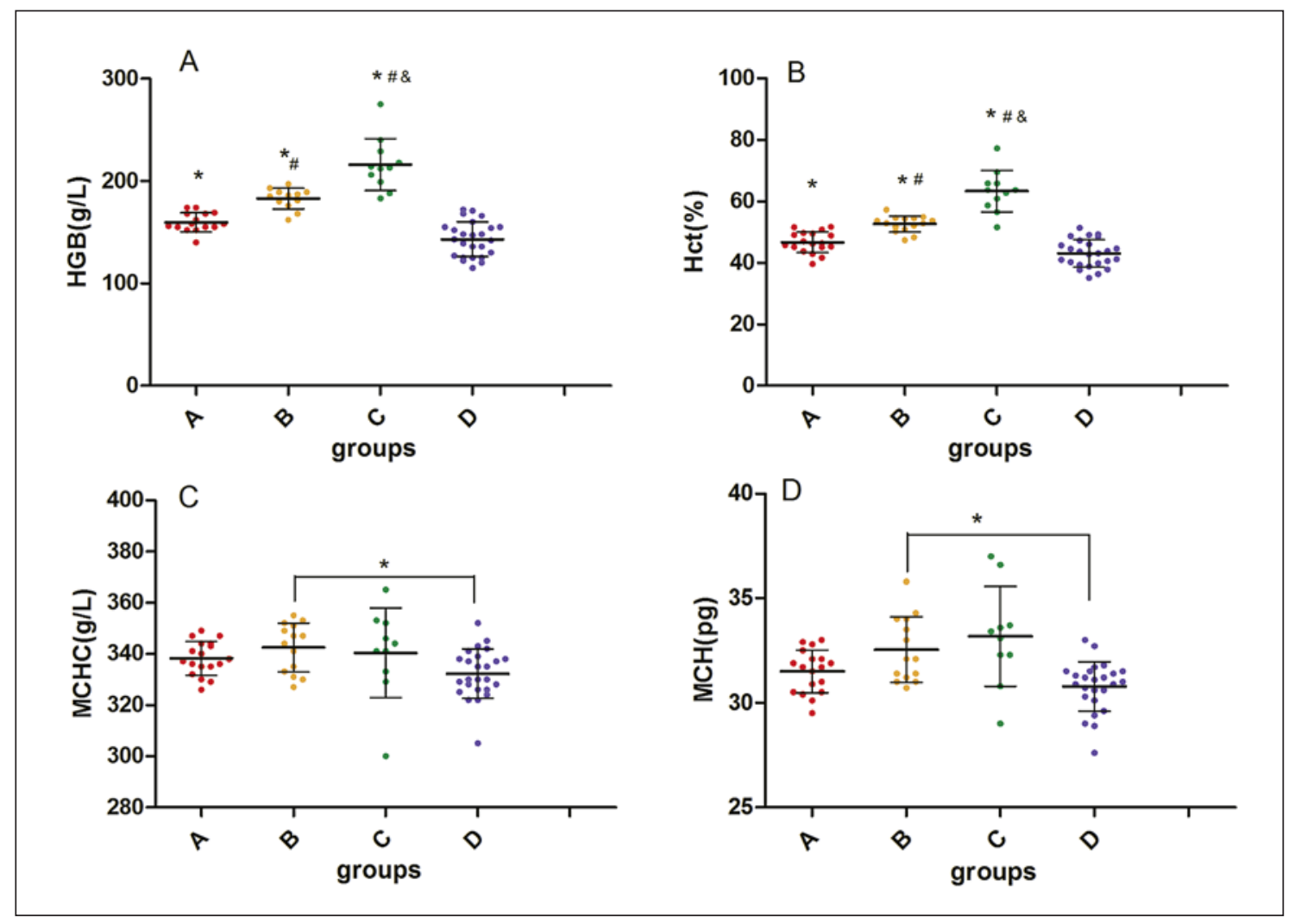

Fig. 1. HGB concentration (A), Hct level (B), MCHC (C), and MCH (D) of WB in all 4 groups. Groups A, B, and $\mathrm{C}$ are from the Tibetan population, and group $\mathrm{D}$ is from the Sichuan Province population. ${ }^{*} p<0.05$ (ANOVA) for groups A, B, and C vs. group D. ${ }^{\#} p<0.05$ (ANOVA) for groups B and C vs. group A, and $p<0.05$ (ANOVA) for group B vs. group C.

\section{Scanning Electron Microscopy}

Scanning electron microscopy (SEM) studies of RBC were performed using a Quanta 250 electron microscope (FEI Company). Blood samples ( $n=5$, randomly chosen from each group) were fixed in phosphate-buffered (pH 7.4) 2.5\% glutaraldehyde for $2 \mathrm{~h}$, mounted on mica slides, washed twice in $0.1 \mathrm{M}$ phosphate buffer ( $\mathrm{pH} 7.4)$, and then dehydrated in graded ethanol $(25,50,70,80,90$, and $100 \%)$. After natural drying and covering with a gold-palladium layer, the samples underwent SEM analysis. The different cell shapes were identified using the Bessis classification [15]. The percentages of discocytes, echinocytes, stomatocyte, spheroechinocytes, and spherocytes were evaluated by counting 400-600 cells per sample in randomly chosen fields. RBC manifesting echinocyte and stomatocyte shapes are capable of returning to the discocyte shape under certain conditions. For example, echinocytes produced by saline washes or by echinocytogenic plasmas are easily reversed to discocytes by resuspension in fresh normal plasma. Echinocytes produced by aging of red cells are not usually reversible by fresh plasma but may be reversible on incubation with adenosine, which allows regeneration of ATP. Thus, these RBC shape changes are considered potentially reversible transformations. In contrast, RBC assuming spherocyte shapes are irreversibly changed cells [16].

\section{RBC Deformability}

RBC deformability was measured using a laser-assisted optical rotational cell analyzer (Lorrca; Maxsis, The Netherlands). In this procedure, $\mathrm{RBC}$ were diluted 1:100 in a polyvinylpyrrolidone solution and subjected to increasing shear stress $(0.3-$
$30.00 \mathrm{~Pa}$ ) at $37.0-37.5^{\circ} \mathrm{C}$. The elongation index (EI) was collected at each stress level and consequently plotted as a deformability curve. Deformability curves were linearized using an Eadie-Hofstee method as published by Stadnick et al. [17]. Two variables were extrapolated using this linearized function: the maximum $\mathrm{EI}\left(\mathrm{EI}_{\max }\right)$ and the shear stress required to reach $50 \%$ of the $\mathrm{EI}_{\max }\left(\mathrm{K}_{\mathrm{I}}\right)$.

\section{SDS-PAGE and Western Blot Analysis}

Proteins ( $6 \mu \mathrm{g}$ protein/lane) were resolved by $10 \%$ SDS-PAGE and electrophoretically transferred to a polyvinylidene difloride membrane (Millipore Immobilon-PSQ). The blocking was performed for $4 \mathrm{~h}$ at room temperature in $5 \%(\mathrm{w} / \mathrm{v})$ bovine serum albumin. Incubation with monoclonal anti-human band 3 antibody produced in a mouse (clone BIII-136, dilution 1:2,000; Sigma-Aldrich) was performed overnight at $4^{\circ} \mathrm{C}$ in $2.5 \%(\mathrm{w} / \mathrm{v})$ bovine serum albumin in TBS $/ 0.1 \%$ Tween 20 . Bands were detected with goat anti-mouse IgG H\&L (HRP; dilution 1:8,000; Abcam) using enhanced chemiluminescence reagents and digitized with Image Scanner II (GE Healthcare, Uppsala, Sweden).

\section{Statistical Analysis}

Data were analyzed using SPSS 17.0 for Windows (SPSS, Inc., Chicago, IL, USA) and are presented as means \pm SD. Repeated measures analysis of variance (ANOVA) was used to compare SRBC from different groups stored for the same length of time and to assess the influence of storage time on SRBC. $p$ values were corrected by Bonferroni correction. 


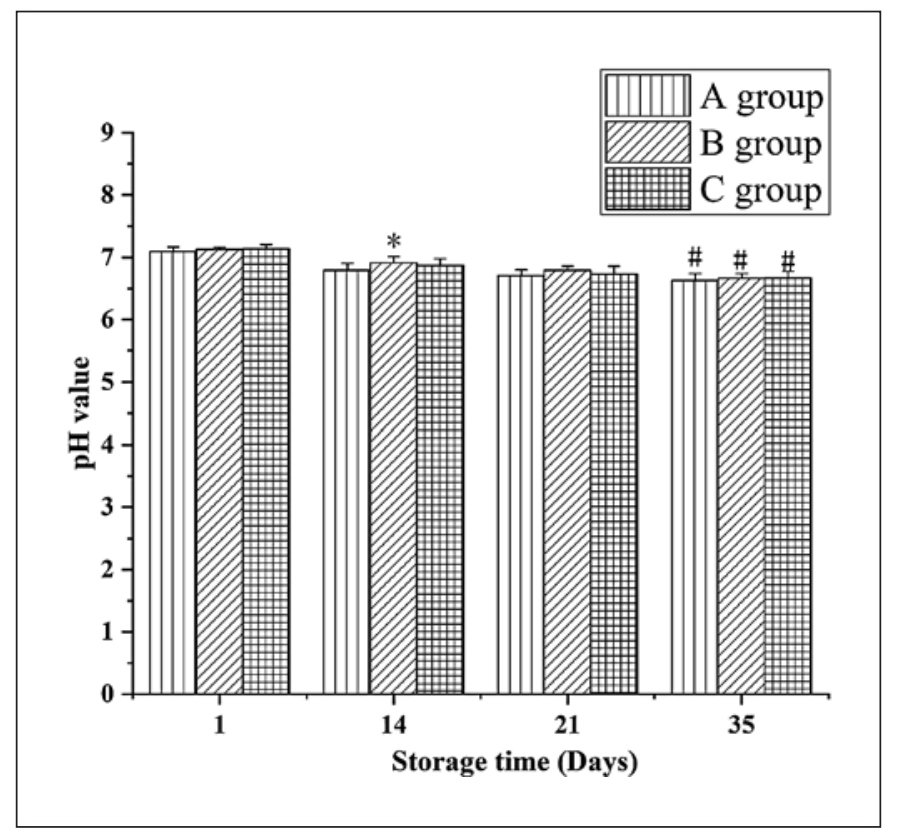

Fig. 2. $\mathrm{pH}$ values of the 3 groups were measured throughout the 35 days of storage. $* p<0.05$ (ANOVA) for the $\mathrm{pH}$ values of group $\mathrm{A}$ vs. group $\mathrm{B}$ on day $14 .{ }^{\#} p<0.05$ (ANOVA) for the $\mathrm{pH}$ values of the 3 groups for day 1 vs. day 35 .

Table 3. MCV for the 3 groups throughout the entire storage period

\begin{tabular}{llll}
\hline $\begin{array}{l}\text { Storage time, } \\
\text { days }\end{array}$ & $\mathrm{MCV}(\mathrm{fL})$ & & \\
\cline { 2 - 4 } & $\mathrm{A}$ & $\mathrm{B}$ & $\mathrm{C}$ \\
\hline 1 & $94.71 \pm 4.55$ & $95.33 \pm 3.99$ & $95.58 \pm 7.07$ \\
14 & $95.61 \pm 4.10$ & $95.97 \pm 3.64$ & $96.13 \pm 7.26$ \\
21 & $95.08 \pm 4.04$ & $96.39 \pm 3.96$ & $96.60 \pm 7.34$ \\
35 & $93.54 \pm 4.11$ & $95.57 \pm 4.39$ & $96.13 \pm 7.58$ \\
\hline
\end{tabular}

\section{Results}

HGB, Hct, Mean Corpuscular HGB Concentration, and Mean Corpuscular HGB Distribution

As shown in Figure 1, with the increase in HGB concentration in the Tibetan population, the Hct level increases correspondingly, while the HGB and Hct levels in groups A, B, and C of Tibetan population are higher than those in the Sichuan population. However, there was no significant difference in the mean corpuscular HGB concentration (MCHC) (tratio of HGB to Hct) or the mean corpuscular HGB $(\mathrm{MCH})$ (ratio of $\mathrm{HGB}$ to $\mathrm{RBC}$, mean HGB content of each RBC) among the 3 groups, and the values in group $\mathrm{B}$ were higher than those in group $\mathrm{D}$ (from Sichuan Province). These results indicate that in the Tibetan population the increase in HGB concentration is not achieved by the increase in HGB in each RBC

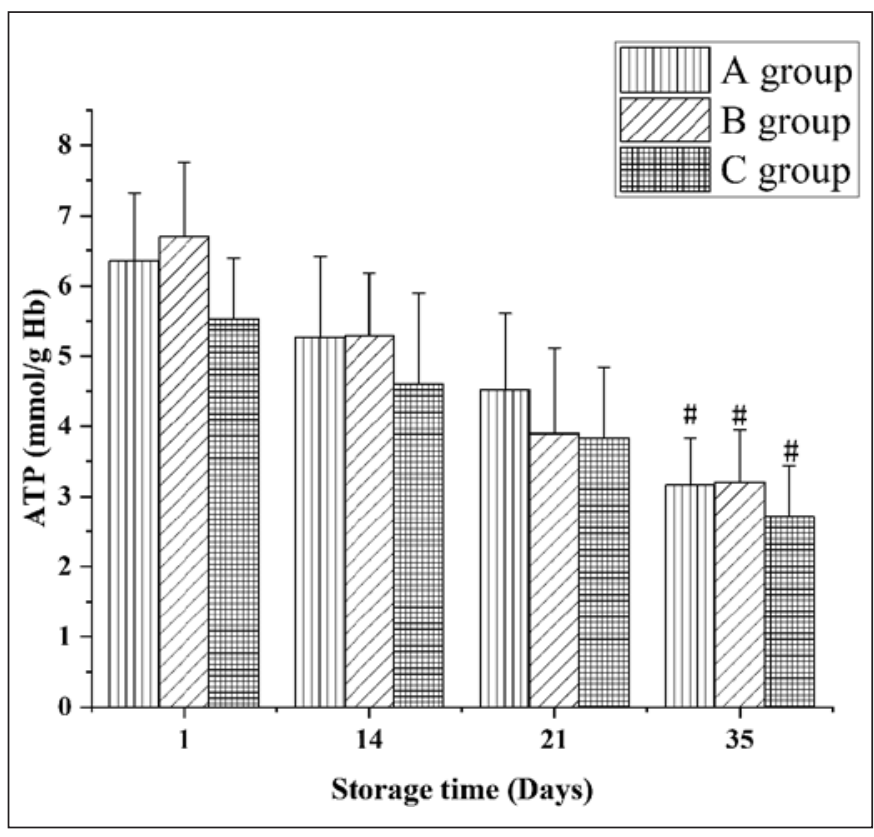

Fig. 3. ATP levels of the 3 groups measured throughout the 35 days of storage. ${ }^{*} p<0.05$ (ANOVA) for the ATP of the 3 groups for day 1 vs. day 35 .

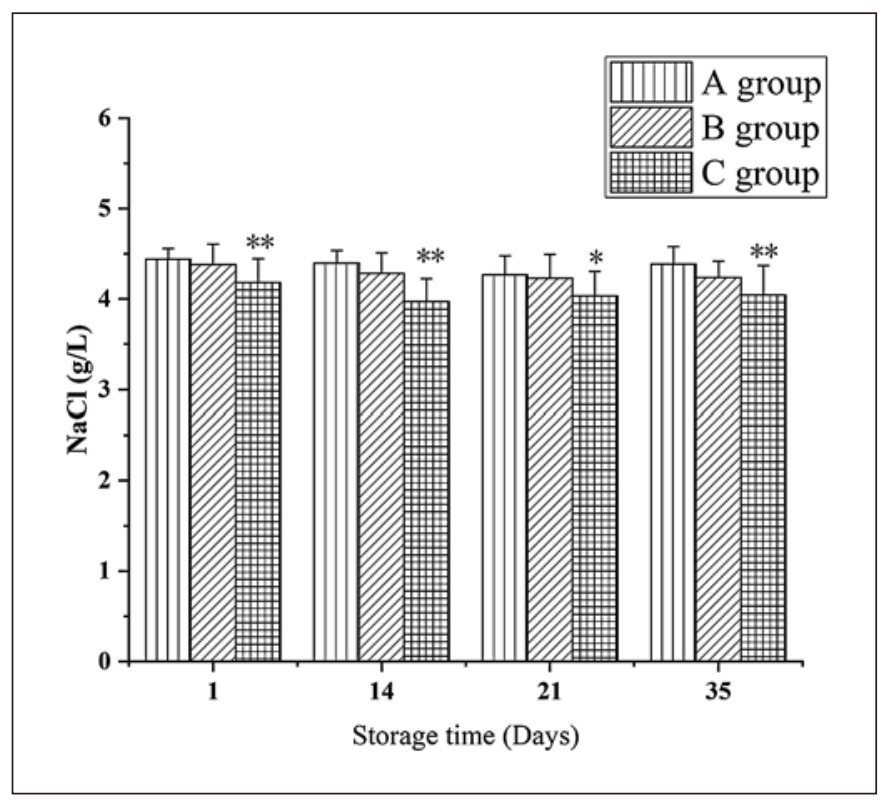

Fig. 4. The osmotic fragility of the 3 groups was measured throughout the 35 days of storage. ${ }^{*} p<0.05$ (ANOVA) for osmotic fragility in groups $\mathrm{A}$ and $\mathrm{C}$ on day $21 .{ }^{* *} p<0.01$ (ANOVA) for osmotic fragility in groups A and C on days 1, 14, and 35.

but rather by the increase in the number of RBC. In other words, HGB and Hct levels change correspondingly. Therefore, we studied morphological changes and deformability of SRBC prepared using WB with different HGB levels of Tibetans. 


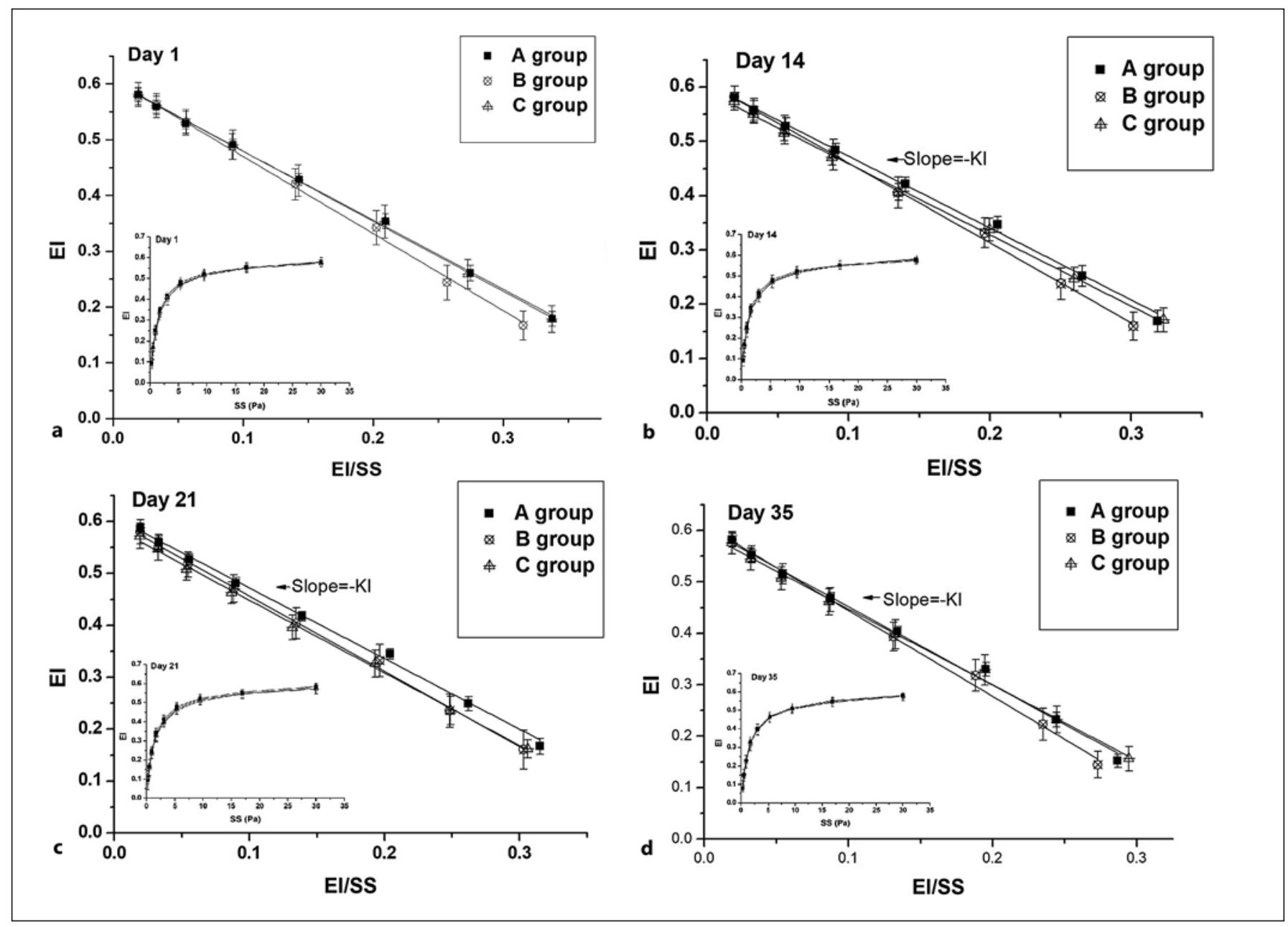

Fig. 5. The Eadie-Hofstee linear data transformation applied to the 3 groups stored on day 1 (a), day 14 (b), day 21 (c), and day 35 (d); 2 variables, i.e., $\mathrm{K}_{\mathrm{I}}$ (slope) and (2) $\mathrm{EI}_{\max }$ (the y-intercept), can be extrapolated from the lines. Inset Deformability curve of the 3 groups obtained from LORCA prior to the Eadie-Hofstee linearization.

\section{Biochemicalanalysis}

The MCV value for all of the groups revealed no difference at each testing point and no relationships with storage time (Table 3 ). The $\mathrm{pH}$ value of groups $\mathrm{A}, \mathrm{B}$, and $\mathrm{C}$ was $7.10 \pm 0.07$ vs. $7.13 \pm 0.03$ vs. $7.14 \pm 0.07$ on day 1 , and it was reduced to $6.63 \pm 0.11$ vs. $6.66 \pm 0.08$ vs. $6.67 \pm$ 0.11 on day 35 (Fig. 2). Although the $\mathrm{pH}$ value of group $\mathrm{B}$ was higher than that of group A on day 14 , the majority of $\mathrm{pH}$ values were not different over the course of preservation. Figure 3 demonstrates that the ATP levels of the 3 groups declined with increasing storage time $(p<0.05)$, but there was no difference among groups at each testing point. Figure 4 shows that $\mathrm{RBC}$ from group $\mathrm{C}$ were more resistant to osmotic stress than $\mathrm{RBC}$ from group A during storage. Fifty percent of RBC from group A and group C lysed at an $\mathrm{NaCl}$ concentration of $4.44 \pm 0.11$ vs. $4.18 \pm$ $0.26 \mathrm{~g} / \mathrm{L}$ on day 1 and then at a concentration of $4.39 \pm$ 0.17 vs. $4.05 \pm 0.33 \mathrm{~g} / \mathrm{L}$ on day 35 . The osmotic fragility between RBC from group B and group A was not different over the course of storage.

\section{RBC Deformability}

The deformation curves for the 3 groups over the course of storage are shown in Figure 5. Throughout the storage period, the RBC deformation curve of the 3 groups showed a similar trend for shear stress, ranging from 0.3 to $30 \mathrm{~Pa}$ during preservation, but more slowly increasing EI values at a high shear stress could be found in all of the groups. The data in Table 4 show no difference in $\mathrm{EI}_{\max }$ values for all of the groups throughout the course of storage. A decrease in $\mathrm{K}_{\mathrm{I}}$ values was observed for group $\mathrm{C}$ compared to group A on day 35 of storage (Table 5; 1.80 \pm 0.17 vs. $1.49 \pm 0.25$ ). Both the $\mathrm{EI}_{\max }$ and the $\mathrm{K}_{\mathrm{I}}$ values of the 3 groups revealed no dependence on storage time.

\section{RBC Morphology}

The SEM of erythrocyte shape for the 3 groups at storage day 1 and day 35 is shown in Figure 6. During the whole preservation period, in all of the groups, the percentage of RBC with a normal shape decreased and the percentage of RBC with an irreversible shape increased. 

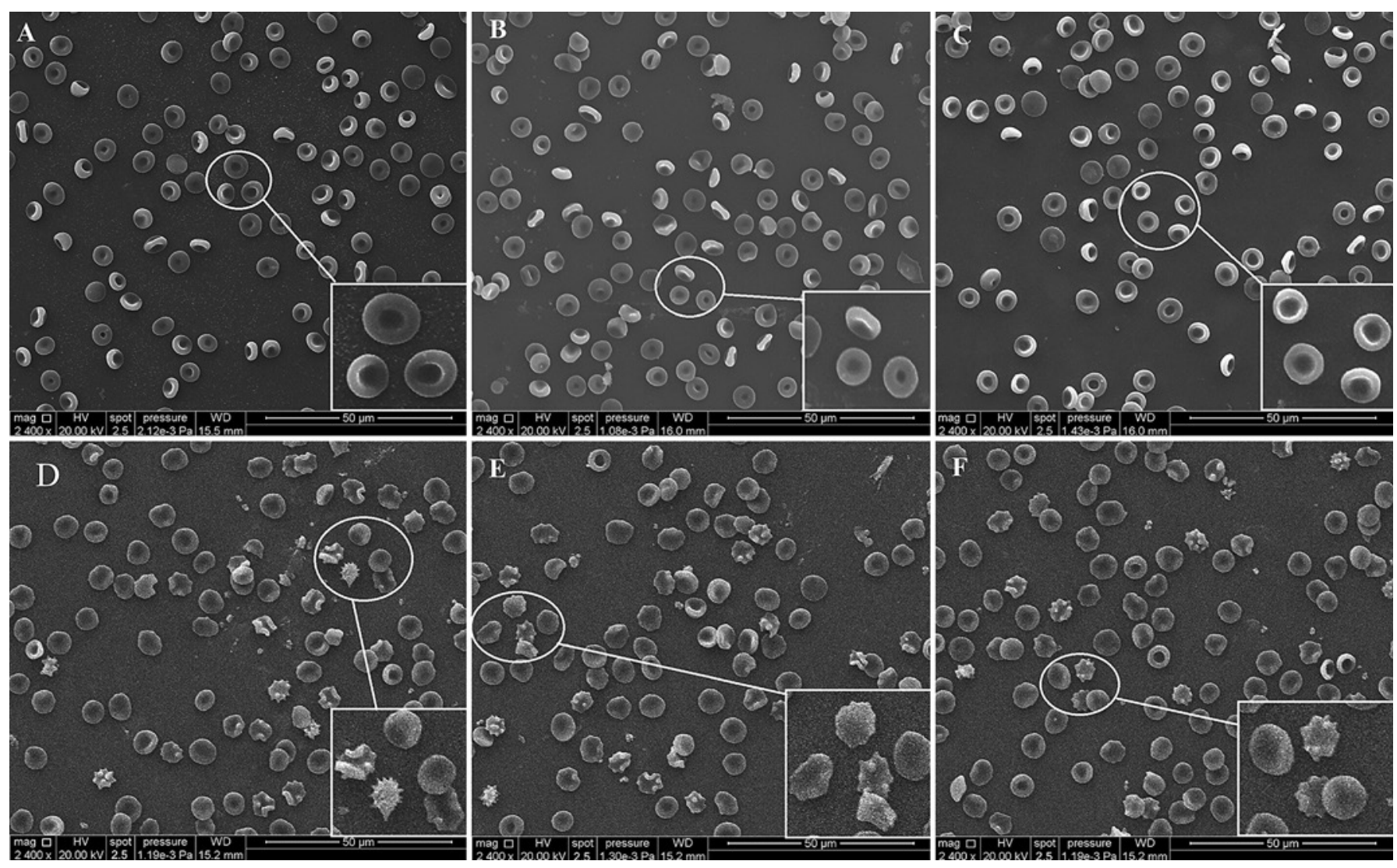

Fig. 6. SEM of stored RBC. One day of storage: groups A (A), B (B), and C (C); 35 days of storage: groups A (D), $\mathrm{B}(\mathbf{E})$, and C (F). Magnification: $\times 2,400$. Scale bar, $50 \mu \mathrm{m}$.

As shown in table 6, from day 21 to day 35, the number of discocyte RBC in groups A and B began to decrease significantly (from $98.05 \pm 1.05$ to $89.59 \pm 7.35$ for group and from $96.47 \pm 5.38$ to $90.41 \pm 4.32$ for group B); correspondingly, the number of echinocytes and stomatocytes in groups $\mathrm{A}$ and $\mathrm{B}$ increased significantly (from 0.27 \pm 0.49 to $5.28 \pm 5.72$ for group $A$ and from $0.11 \pm 0.16$ to $4.05 \pm 2.50$ for group B). For group C, though the percentage of normal RBC did not change noticeably from day 21 to day 35 , the percentage of cells with an irreversible shape increased from $2.36 \pm 5.12$ to $5.24 \pm 1.91$ and the percentage of $\mathrm{RBC}$ with a reversible shape decreased from $3.15 \pm 4.96$ to $0.94 \pm 0.93$.

No difference was observed for groups A and B during the entire storage time. Before 14 days of storage, groups $\mathrm{A}$ and $\mathrm{C}$ had similar morphological alternations. However, in RBC stored for 21 days, the percentage of cells with a normal shape in group $\mathrm{C}$ was lower than that in $\mathrm{A}$ group ( $94.49 \pm 9.06$ vs. $98.05 \pm 1.05)$, while the percentage of cells with an irreversible shape in group $\mathrm{C}$ was $2.36 \pm$ 5.12 , i.e., higher than that in group A $(0.27 \pm 0.49)$. When the storage time was extended to 35 days, the difference between the percentage of normal RBC and RBC with an irreversible shape in groups $\mathrm{A}$ and $\mathrm{C}$ was reduced but the
Table 4. $\mathrm{EI}_{\max }$ for the $3 \mathrm{SRBC}$ throughout the entire storage period

\begin{tabular}{llll}
\hline $\begin{array}{l}\text { Storage time, } \\
\text { days }\end{array}$ & $\mathrm{EI}_{\max }$ & & \\
\cline { 2 - 4 } & $\mathrm{A}$ & $\mathrm{B}$ & $\mathrm{C}$ \\
\hline 1 & $0.60 \pm 0.01$ & $0.60 \pm 0.02$ & $0.62 \pm 0.02$ \\
14 & $0.61 \pm 0.02$ & $0.62 \pm 0.03$ & $0.59 \pm 0.02$ \\
21 & $0.61 \pm 0.03$ & $0.59 \pm 0.03$ & $0.59 \pm 0.05$ \\
35 & $0.62 \pm 0.02$ & $0.62 \pm 0.02$ & $0.61 \pm 0.03$ \\
\hline
\end{tabular}

Table 5. $\mathrm{K}_{\mathrm{I}}$ for the $3 \mathrm{SRBC}$ throughout the entire storage period

\begin{tabular}{llll}
\hline $\begin{array}{l}\text { Storage time, } \\
\text { days }\end{array}$ & $\mathrm{K}_{\mathrm{I}}$ & & \\
\cline { 2 - 4 } & $\mathrm{A}$ & $\mathrm{B}$ & $\mathrm{C}$ \\
\hline 1 & $1.57 \pm 0.30$ & $1.72 \pm 0.62$ & $1.41 \pm 0.31$ \\
14 & $1.41 \pm 0.22$ & $1.74 \pm 0.43$ & $1.25 \pm 0.26$ \\
21 & $1.57 \pm 0.28$ & $1.73 \pm 0.63$ & $1.32 \pm 0.34$ \\
35 & $1.80 \pm 0.17$ & $2.03 \pm 0.47$ & $1.49 \pm 0.25^{*}$ \\
\hline
\end{tabular}

* $t$ test; $p<0.05$ for group C vs. group A on day of 35 .

Transfus Med Hemother 2021;48:210-219 
Table 6. SEM of erythrocyte shape and classification

\begin{tabular}{lllll}
\hline $\begin{array}{l}\text { Storage } \\
\text { time, days }\end{array}$ & 1 & 14 & 21 & 35 \\
\hline \multicolumn{5}{c}{ Normal shape (discocyte) } \\
$\mathrm{A}$ & $99.20 \pm 1.23$ & $98.44 \pm 2.07$ & $98.05 \pm 1.05$ & $89.59 \pm 7.35^{\# \Psi}$ \\
$\mathrm{B}$ & $99.57 \pm 0.63$ & $98.05 \pm 3.05$ & $96.47 \pm 5.38$ & $90.41 \pm 4.32^{\# \Psi}$ \\
$\mathrm{C}$ & $99.60 \pm 0.59$ & $97.86 \pm 1.4$ & $94.49 \pm 9.06^{*}$ & $93.82 \pm 2.47^{\#}$ \\
\hline Reversible shape (echinocytes and stomatocytes) \\
$\mathrm{A}$ & $0.80 \pm 1.23$ & $1.47 \pm 1.89$ & $1.68 \pm 1.13$ & $5.13 \pm 2.14^{\# \Psi}$ \\
$\mathrm{B}$ & $0.43 \pm 0.63$ & $1.79 \pm 3.00$ & $3.42 \pm 5.41$ & $5.54 \pm 2.58^{\#}$ \\
$\mathrm{C}$ & $0.40 \pm 0.59$ & $1.97 \pm 1.50$ & $3.15 \pm 4.96$ & $0.94 \pm 0.93^{* \Psi}$ \\
\hline Irreversible shape (spheroechinocytes and spherocytes) & \\
$\mathrm{A}$ & 0 & $0.09 \pm 0.19$ & $0.27 \pm 0.49$ & $5.28 \pm 5.72^{\# \Psi}$ \\
$\mathrm{B}$ & 0 & $0.16 \pm 0.25$ & $0.11 \pm 0.16$ & $4.05 \pm 2.50^{\# \Psi}$ \\
$\mathrm{C}$ & 0 & $0.17 \pm 0.37$ & $2.36 \pm 5.12^{* \#}$ & $5.24 \pm 1.91^{\# \Psi}$ \\
\hline
\end{tabular}

The number of samples was $5 .^{*} p<0.05$ (ANOVA) for RBC with a normal shape and an irreversible shape in group $C$ vs. group A on day 35. ${ }^{\#} p<0.05$ (ANOVA) for classification of the cell morphology of the 3 groups on day 1 vs. day $35 .{ }^{\Psi} p<0.05$ (ANOVA) for classification of the cell morphology of the 3 groups on day 21 vs. day 35 .

difference in the percentage of RBC with a reversible shape was increased $(5.13 \pm 2.14$ for group A and $0.94 \pm$ 0.93 for group C).

\section{RBC Membrane Protein Analysis}

SDS-PAGE of RBC membrane proteins after 1 and 35 days of storage revealed that higher molecular weight (HMW) bands occurred after 35 days of storage in the 3 groups (Fig. 7). Western blot analysis of band 3 protein on the RBC membrane revealed more clear bands at a HMW in the 3 groups after 35 days of storage. More apparent clustering spots in the region of $150-250 \mathrm{kDa}$ could be observed in group C compared to group A (Fig. 8).

\section{Discussion}

In an HA situation, in response to the insufficient amount of oxygen, the bone marrow is stimulated by an erythropoietic factor to increase RBC production, resulting in an increase in the levels of Hct and HGB [18]. Due to the wide area and large altitude span in Tibet, plateau residents living in different areas may have different extents of HGB and Hct increase. However, the storage quality of SRBC prepared using WB from Tibetans with different HGB and Hct levels was still unknown. The results in Figure 1 indicate that Hct and HGB levels increased correspondingly with the increase in $\mathrm{RBC}$ in $\mathrm{Ti}$ bet. Thus, this paper compared the morphological and deformation lesions of SRBC from plateau WB with dif-

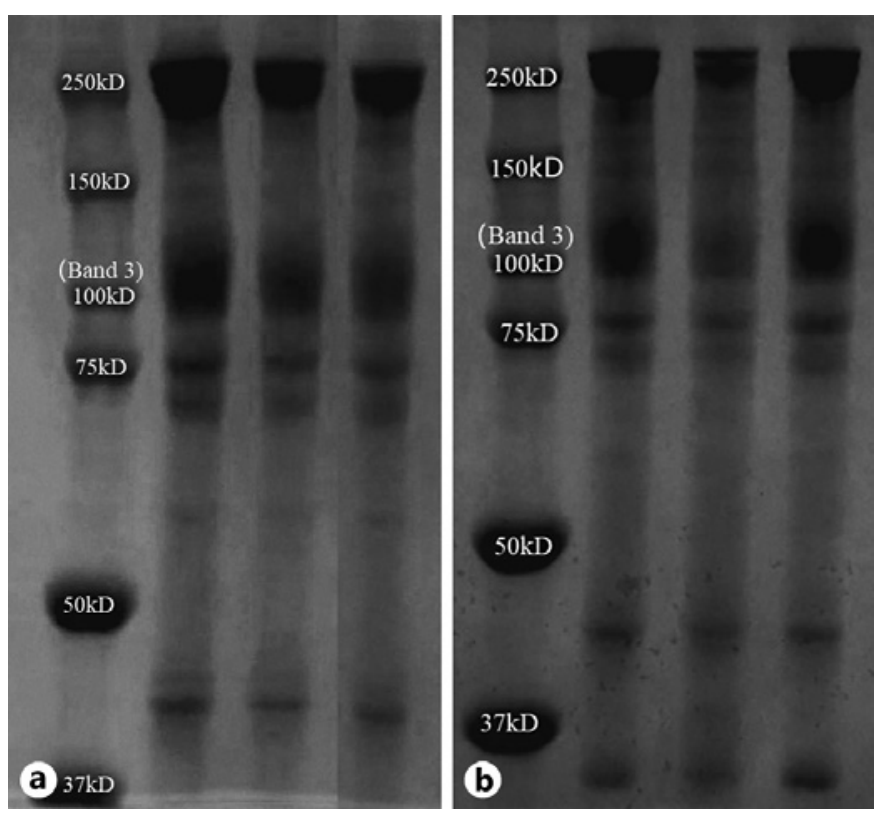

Fig. 7. SDS-PAGE analysis of erythrocyte membrane proteins from the 3 groups at 1 (a) and 35 (b) days of storage.

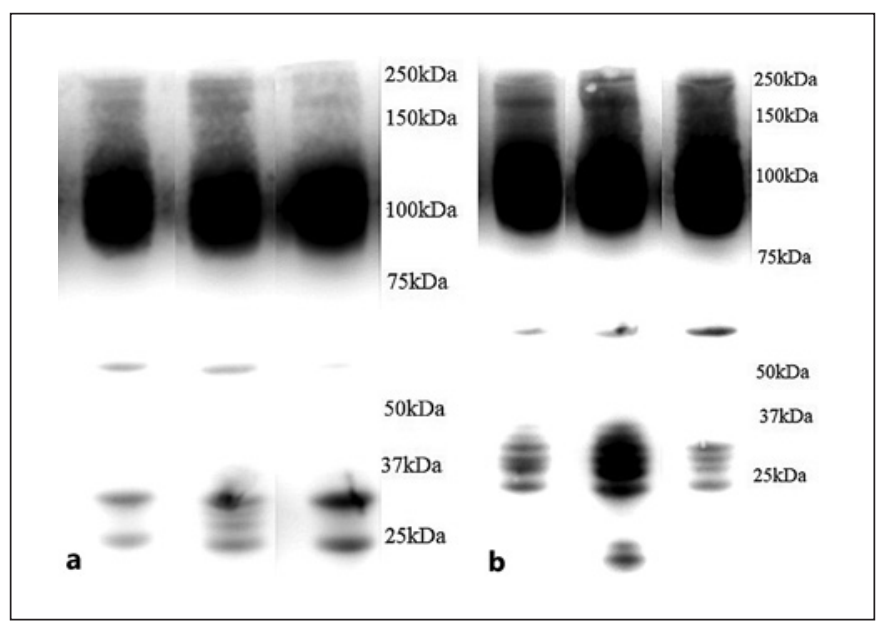

Fig. 8. Western blot of erythrocyte membrane band 3 proteins on RBC membranes from the 3 groups at 1 (a) and 35 (b) days of storage.

ferent HGB levels during a 35-day storage period to discuss the clinical potential of plateau SRBC.

During storage, RBC undergo various metabolic, structural, and morphological changes [19]. In response to the insufficient amount of oxygen, the HGB and Hct levels of people who live long term in Tibet areas may be enhanced compared to those of people who live in the low land [18]. The increased HGB and Hct values will lead to hyperviscosity, which may affect RBC morphology during storage and further affect RBC deformability, which is an important factor of RBC oxygen-carrying capacity after clinical transfusion. 
$\mathrm{MCV}$ reflects the overall change in $\mathrm{RBC}$ volume, which is importantly determined by the shape of RBC during storage. Some findings have suggested that, with the prolongation of storage time, the MCV of SRBC gradually increases due to the appearance of swollen and spherical cells during storage [20]. However, our data showed no difference in MCV among the 3 groups during the whole storage period and no correlation with storage time for each group, indicating that both HGB and storage time did not affect the overall volume of RBC. Our SEM findings revealed that 35 days of storage did not cause an obvious difference in the percentage of abnormal cells in the 3 groups. The percentage of cells with an irreversible shape in the 3 groups on day 35 was only about $5 \%$, and percentage of discocyte-shaped cells for the 3 groups remained around $90 \%$. Such a small morphological change indeed may not account for the total volume of RBC. Additionally, $\mathrm{RBC}$ with an irreversible shape cannot accomplish their normal oxygen-carrying function as they are unable to return to their normal shape and travel in and out of the capillaries after intravenous infusion. Our data showed no difference in RBC with an irreversible shape in the 3 groups, indicating that transfusion of SRBC prepared using WB with high HGB and Hct levels may not reduce the oxygen-carrying capacity. Similar alternations in cell morphology in the 3 groups may be attributed to no difference in ATP and $\mathrm{pH}$ values during storage. In fact, maintenance of a normal morphology of RBC requires energy sources, such as ATP [21]. The insufficient ATP-dependent Na-K pump activity at the RBC membrane over the storage duration resulted in the double concave disc erythrocytes converting to an abnormal shape [20]. Cells with a reversible shape, like echinocytes and stomatocytes, are capable of returning to a discocyte shape with normalization of the ATP level. In contrast, cells with an irreversible shape, like spheroechinocytes and spherocytes, are not readily reversed with normalization of the ATP level or even after RBC transfusion [18, 21]. The $\mathrm{pH}$ value was another critical factor for RBC shape. $\mathrm{pH}$ variations affected the membrane potential, resulting in shape alterations [22]. Blasi et al. [13] mentioned that a rapid decline in internal $\mathrm{pH} /$ external $\mathrm{pH}$ over the course of storage reflected changes in cation homeostasis affecting enzyme kinetics, resulting in destruction of the structure of RBC. In our study, storage time induced a decline in ATP and $\mathrm{pH}$ values, which was responsible for an approximately $10 \%$ reduction in the percentage of cells with a normal shape during the whole storage duration. The lack of differences in ATP and $\mathrm{pH}$ values in the 3 groups explained similar morphological changes at the majority of testing points. Day 21 of preservation seemed to be a turning point for morphological changes in the 3 groups. After 21 days of storage, the number of RBC with an irreversible shape in the 3 groups significantly increased. When RBC were stored from 21 to 35 days, the reduction in the number of biconcave diskshaped RBC in groups A and B group was due to transformation into echinocytes and stomatocytes with a reversible shape and into spheroechinocytes and spherocytes with an irreversible shape. For group $\mathrm{C}$, in the last 2 weeks of storage no significant decrease appeared in the number of normal RBC, and the morphological alternation mainly occurred in the transformation from $\mathrm{RBC}$ with a reversible shape to $\mathrm{RBC}$ with an irreversible shape.

$\mathrm{RBC}$ morphology has been proposed to be a major determinant of RBC deformability, because biconcave diskshaped cells with a high specific surface area are capable of passing through capillaries. RBC with a low deformability sequestered in the spleen may be destructed [22]. In this study, we used an Eadie-Hofstee curve to analyze $\mathrm{RBC}$ deformability and rigidity. The inlet graph in Figure 5 shows that HGB and Hct induced minor changes in deformability with stress ranging from 0.3 to $30 \mathrm{~Pa}$ at each testing point, which implied that when stored RBC from 3 SRBC were transfused into patients they were able to flow through microcapillaries with a similar folding capability. However, the more slowly increasing EI value of the 3 SRBC indicated a poor stretching capability of RBC at a higher shear stress. According to the Eadie-Hofstee analysis [23], $\mathrm{EI}_{\max }$ values illustrated how far a population of $\mathrm{RBC}$ can be physically stretched and thus they are an indicator of overall $\mathrm{RBC}$ deformability; $\mathrm{K}_{\mathrm{I}}$ values illustrated how much force is required for $\mathrm{RBC}$ to reach their maximal stretching capacity they and are therefore an indicator of RBC rigidity [17]. Tables 4 and 5 show that no significant difference in $\mathrm{EI}_{\max }$ values in the $3 \mathrm{SRBC}$ throughout the course of storage, but unexpectedly lower $\mathrm{K}_{\mathrm{I}}$ values were found in group $\mathrm{C}$ at the end of storage. It seemed that high levels of HGB and Hct in donated blood had less of an effect on plateau RBC deformability but they had positive effects on $\mathrm{RBC}$ rigidity during the whole preservation period.

Although most of the existing literature consistently reports a decreased deformability of stored RBC [24], our data shows unchanged deformability of stored RBC caused by storage, which is in accordance with the results of Farge et al. [25] and Zheng et al. [26] which showed that the deformability of stored RBC was not significantly reduced up to 5 weeks [27]. Deformability is mainly determined by the surface area-to-volume ratio $(\mathrm{S} / \mathrm{V})$. Both an increase and a decrease in S/V may lead to a decrease in deformability [28]. The fact that there was no difference in the deformability of the 3 plateau RBC may be due to the lack of a significant difference in the number of RBC with an abnormal shape that had a reduction in $\mathrm{S} / \mathrm{V}$. Additionally, it has previously been shown that cell deformability is unaffected at $\mathrm{pH}$ values ranging between 6.4 and 7.7 [29]. In our study, the $\mathrm{pH}$ value of the 3 plateau 
SRBC at the end of storage was still within this limit, further suggesting that high HGB and Hct levels did not impact the deformability of plateau RBC during preservation. However, our osmotic fragility and membrane rigidity results indicate that RBC from group $\mathrm{C}$ with extremely high HGB and Hct levels seemed to have a better membrane elasticity. We further did an SDS-PAGE analysis of RBC membrane proteins and analyzed the alternation of band 3 protein in this study, because damage to the protein cytoskeleton can reduce the membrane elasticity and increase RBC fragility [30]. Band 3 protein complexes play a critical role in maintaining the structural integrity and stability of the RBC membrane [31]. Some investigators believe that aging $\mathrm{RBC}$ produce clustering band 3 protein $(>100 \mathrm{kDa})$ [31]. Our SDS-PAGE showed the storage induced cross-linking of proteins on the membrane of plateau RBC (more clear bands appeared at HMW). Western blot analysis of band 3 protein demonstrated that different degrees of clustering occurred at the end of the preservation period for the 3 plateau RBC. Interestingly, our data showed less remarkable bands at $\mathrm{HMW}$ for $\mathrm{RBC}$ from group $\mathrm{C}$, suggesting a weaker clustering degree of band 3 protein at 35 days of storage. This finding can be considered to explain the less rigid cells of group C. It is probable that the different HGB and Hct levels in plateau WB resulted in modification of some components of the membrane, leading to alternation of the rigidity of plateau $\mathrm{RBC}$, but this modification was minor and did not detrimentally affect the overall ultrastructure of plateau RBC.

\section{Limitations}

Some limitations of this study should be considered. First, the plateau WB samples were limited due to the small number of donating volunteers. Second, the samples were only from male volunteers. Third, the volunteers were often not fully comparable because they were at different altitudes. Finally, in this study, we provide evidence that the effects of different HGB concentrations on factors contributing to morphological changes and deformability, such as ATP, $\mathrm{pH}$, band 3 protein, and osmotic fragility but did not take into account the phosphatidylserine exposure that is reported as another determinant for membrane deformability and morphology.

\section{Conclusions}

In conclusion, we found that groups $\mathrm{B}$ and $\mathrm{C}$ had spherical RBC numbers and membrane deformability similar to those of group A over the course of storage. This similarity may be due to the lack of a difference in
ATP and $\mathrm{pH}$ values during the preservation period. However, a better membrane elasticity was showed in RBC from group $\mathrm{C}$ in comparison to $\mathrm{RBC}$ from group $\mathrm{A}$ at the end of storage. This finding may be explained by weaker clustering band 3 protein on $\mathrm{RBC}$ membranes from group $\mathrm{C}$ at the end of preservation, leading us to speculate that different HGB and Hct levels might not affect the overall plateau RBC ultrastructure but may alter some components on the cell membrane during storage. Therefore, we concluded that the high HGB and Hct of SRBC did not worsen $\mathrm{RBC}$ morphology and deformability during 35 days of preservation in bank conditions. Such conclusions can be considered as a reference for clinical transfusion of plateau WB with high HGB and Hct levels.

\section{Acknowledgement}

We thank all the blood donors and blood collection personnel who participated in this research. We also thank the laboratory department staff of the Tibet Autonomous Region Chengdu Office Hospital for their help with the analysis of routine biochemical test data.

\section{Statement of Ethics}

As per the hospital transfusion policy, informed consent was obtained from each of the participants included in this study. All of the procedures performed in this study involving human participants were in accordance with the ethical standards of the institutional ethics committee and with the 1964 Helsinki Declaration and its later amendments or comparable ethical standards. The study protocol was approved by the Institute of Blood Transfusion Ethics Committee (registration No. 201712).

\section{Disclosure Statement}

The authors declare that they have no conflict of interests relevant to this paper.

\section{Funding Sources}

This work was financially sponsored by the Tibet Autonomous Region Science and Technology Project (No. XZ201703-GB-02) and the Sichuan Science and Technology Project (No. 2018JY0571).

\section{Author Contributions}

D.H. and R.Z. contributed to data interpretation and drafting of this paper. H.W., J.L., and X.W. contributed to conceptualization and the study design. W.L., Z.H., and X.Z. helped with data acquisition and critical revision of the draft of this work. 


\section{References}

1 Sullivan MT, Cotten R, Read EJ, Wallace EL. Blood collection and transfusion in the United States in 2001. Transfusion. 2007 Mar; 47(3):385-94

2 Hess JR. An update on solutions for red cell storage. Vox Sang. 2006 Jul;91(1):13-9.

3 Zimrin AB, Hess JR. Current issues relating to the transfusion of stored red blood cells. Vox Sang. 2009;96(2):93-103.

4 Obrador R, Musulin S, Hansen B. Red blood cell storage lesion. J Vet Emerg Crit Care (San Antonio). 2015 Mar-Apr;25(2):187-99.

5 Mustafa I, Al Marwani A, Mamdouh Nasr K, Abdulla Kano N, Hadwan T. Time Dependent Assessment of Morphological Changes: Leukodepleted Packed Red Blood Cells Stored in SAGM. BioMed Res Int. 2016;2016: 4529434.

6 Narla J, Mohandas N. Red cell membrane disorders. Int J Lab Hematol. 2017 May;39(Suppl 1):47-52.

7 Secomb TW, Styp-Rekowska B, Pries AR Two-dimensional simulation of red blood cell deformation and lateral migration in $\mathrm{mi}$ crovessels. Ann Biomed Eng. 2007 May;35(5): 755-65.

8 Waugh RE, Narla M, Jackson CW, Mueller TJ, Suzuki T, Dale GL. Rheologic properties of senescent erythrocytes: loss of surface area and volume with red blood cell age. Blood. 1992 Mar;79(5):1351-8.

9 Winslow RM, Samaja M, West JB. Red cell function at extreme altitude on Mount Everest. J Appl Physiol. 1984 Jan;56(1):109-16.

10 Wu T, Wang X, Wei C, Cheng H, Wang X, Li $\mathrm{Y}$, et al. Hemoglobin levels in Qinghai-Tibet: different effects of gender for Tibetans vs. Han. J Appl Physiol (1985). 2005 Feb;98(2): 598-604.

11 Zhang R, Yu X, Shen Y, Yang C, Liu F, Ye S, et al. Correlation between $\mathrm{RBC}$ changes and coagulation parameters in high altitude population. Hematology. 2019 Dec;24(1):325-30.
12 Zhong R, Liu H, Wang H, Li X, He Z, Gangla M, et al. Adaption to High Altitude: An Evaluation of the Storage Quality of Suspended Red Blood Cells Prepared from the Whole Blood of Tibetan Plateau Migrants. PLoS One. 2015 Dec;10(12):e0144201.

13 Blasi B, D'Alessandro A, Ramundo N, Zolla L. Red blood cell storage and cell morphology. Transfus Med. 2012 Apr;22(2):90-6.

14 Blood Standards Committee of the Ministry of Health of China. Standards for blood storage. Health industry standard of the People's Republic of China: WS 399-2012. 2013.

15 Bessis M. Red cell shapes. An illustrated classification and its rationale. Nouv Rev Fr Hematol. 1972 Nov-Dec;12(6):721-45.

16 Berezina TL, Zaets SB, Morgan C, Spillert CR, Kamiyama M, Spolarics Z, et al. Influence of storage on red blood cell rheological properties. J Surg Res. 2002 Jan;102(1):6-12.

17 Stadnick H, Onell R, Acker JP, Holovati JL. Eadie-Hofstee analysis of red blood cell deformability. Clin Hemorheol Microcirc. 2011; 47(3):229-9.

18 Reynafarje C, Ramos J, Faura J, Villavicencio D. Humoral Control of Erythropoietic Activity in Man during and after Altitude Exposure. Proc Soc Exp Biol Med. 1964 Jul;116(3): 649-50.

19 Hess JR. Red cell changes during storage. Transfus Apheresis Sci. 2010 Aug;43(1):51-9.

20 Sollberger T, Walter R, Brand B, Contesse J, Meredith DO, Reinhart WH. Influence of prestorage leucocyte depletion and storage time on rheologic properties of erythrocyte concentrates. Vox Sang. 2002 May; 82(4): 191-7.

21 Betz T, Lenz M, Joanny JF, Sykes C. ATP-dependent mechanics of red blood cells. Proc Natl Acad Sci USA. 2009 Sep;106(36):15320-
22 Wallas $\mathrm{CH}$. Sodium and potassium changes in blood bank stored human erythrocytes. Transfusion. 1979 Mar-Apr;19(2):210-5.

23 Mohandas N, Chasis JA. Red blood cell deformability, membrane material properties and shape: regulation by transmembrane, skeletal and cytosolic proteins and lipids. Semin Hematol. 1993 Jul;30(3):171-92.

24 Barshtein G, Manny N, Yedgar S. Circulatory risk in the transfusion of red blood cells with impaired flow properties induced by storage. Transfus Med Rev. 2011 Jan;25(1):24-35

25 Farges E, Grebe R, Baumann M. Viscoelastic and biochemical properties of erythrocytes during storage with SAG-Mat+4 degrees C. Clin Hemorheol Microcirc. 2002;27(1):1-11.

26 Zheng Y, Chen J, Cui T, Shehata N, Wang C, Sun Y. Characterization of red blood cell deformability change during blood storage. Lab Chip. 2014 Feb;14(3):577-83.

27 Henkelman S, Dijkstra-Tiekstra MJ, de Wildt-Eggen J, Graaff R, Rakhorst G, van Oeveren W. Is red blood cell rheology preserved during routine blood bank storage? Transfusion. 2010 Apr;50(4):941-8.

28 Cluitmans JC, et al. Red blood cell deformability during storage: towards functional proteomics and metabolomics in the Blood Bank. Blood Transfus. 2012;10(Suppl 2):s128.

29 Johnson RM. pH effects on red cell deformability. Blood Cells. 1985;11(2):317-21.

30 Wolfe LC, Byrne AM, Lux SE. Molecular defect in the membrane skeleton of blood bankstored red cells. Abnormal spectrin-protein 4.1-actin complex formation. J Clin Invest. 1986 Dec;78(6):1681-6.

31 Lutz HU. Naturally occurring anti-band 3 antibodies in clearance of senescent and oxidatively stressed human red blood cells. Transfus Med Hemother. 2012 Oct;39(5):321-7. 